\title{
Origem, ramificação e distribuição do nervo radial no braço do gato doméstico (Felis catus domesticus, Linnaeus 1758)
}

Gregório Corrêa GUIMARÃES Márcia Rita Fernandes MACHADO $^{1}$

André Luiz Quagliatto SANTOS 2

Maria Angélica MIGLINO ${ }^{3}$ José Wanderley CATTELAN ${ }^{1}$

\section{Correspondência para:}

Departamento de Morfologia e Fisiologia Animal da FCAV/UNESP. Via de Acesso Professor Paulo Donato Castellane, s/n. 14884-900. Jaboticabal - SP. E-mail: gregorio@fcav.unesp.br

Recebido para publicação: 16/09/2005 Aprovado para publicação: 27/03/2007

\author{
Faculdade de Ciências Agrárias, Universidade de Marília, Marília - SP \\ ${ }^{2}$ Faculdade de Medicina Veterinária da Universidade Federal de Uberlândia - MG \\ ${ }^{3}$ Faculdade de Medicina Veterinária e Zootecnia da Universidade de São Paulo - SP
}

\section{Resumo}

Estudou-se a origem, a distribuição e a ramificação do nervo radial em 30 gatos adultos, 15 machos e 15 fêmeas, sem raça definida, mediante dissecação macroscópica, após a fixação dos espécimes em solução aquosa de formaldeído a $10 \%$. O referido nervo originou-se dos ramos ventrais do sexto (18,33\%), sétimo (100,0 $\%)$ e oitavo $(100,0 \%)$ nervos espinhais cervicais e do ramo ventral do primeiro $(100,0 \%)$ nervo espinhal torácico. O nervo radial cedeu ramos musculares em todos os animais para os músculos tensor da fáscia antebraquial, cabeça longa do tríceps braquial, cabeça acessória do tríceps braquial, cabeça medial do tríceps braquial, cabeça lateral do tríceps braquial e ancôneo, emitindo de 14 a 25 ramos nervosos na região do braço. $\mathrm{O}$ ramo ventral do sexto nervo espinhal cervical apresentou diferença significativa $(p<0,05)$ em relação ao sexo dos animais.

\section{Introdução}

O cão e o gato sofrem, freqüentemente, traumatismos nos órgãos locomotores, decorrentes de atropelamentos, acidentes com projéteis, injeções mal aplicadas etc., provocando luxações e/ou fraturas, constituindo-se numa das causas mais comuns dos déficits ocorridos nos nervos espinhais. Estes acontecimentos podem provocar desde simples compressão até a transecção completa de um ou mais nervos, ou até, a avulsão de suas raízes nervosas $1,2,3,4,5,6,7,8$.

Um quadro de lesão nervosa se considerado isoladamente não representa, geralmente, risco de vida, mas suas seqüelas podem levar à incapacidade permanente ou à morte ${ }^{7}$. Desse modo, a intervenção do cirurgião para reparar a fratura e as estruturas lesionadas torna-se necessária. Tais procedimentos são delicados, uma vez que a anatomia e a fisiologia dos nervos espinhais, constituintes do sistema nervoso periférico são complexas ${ }^{?}$.

A regeneração inadequada de um nervo espinhal pós-trauma, representa um dos maiores problemas no tratamento de pacientes lesionados. Então, para que sejam atendidas as exigências para a cura de um nervo reparado, o cirurgião deve possuir informações morfológicas precisas sobre os nervos espinhais ${ }^{7}$.

Portanto, o presente estudo foi realizado com propósito de conhecer, examinar e descrever as variações na origem, ramificação e distribuição do nervo radial no braço do gato doméstico, com intuito de oferecer embasamentos para intervenções cirúrgicas, tendo-se em vista, a importância do referido nervo na inervação motora do membro torácico.

\section{Material e Método}

Para realização deste estudo, foram utilizados 30 gatos adultos, sem raça definida, 15 fêmeas e 15 machos, provenientes do Centro de Controle de Zoonoses do Município de Jaboticabal - SP, fixados imediatamente após o sacrifício em solução 
aquosa de formaldeído a $10 \%$ e imersos em recipientes contendo essa mesma solução.

O estudo foi realizado no Laboratório de Anatomia do Departamento de Morfologia e Fisiologia Animal da Faculdade de Ciências Agrárias e Veterinárias, UNESP, Câmpus de Jaboticabal.

Após a fixação dos animais, procedeuse a dissecação mediante incisão mediana ventral na região cervical, iniciando-se na altura da cartilagem tireóide da laringe até o processo xifóide do esterno, e outra, perpendicular a esta, desde o esterno à articulação úmero-rádio-ulnar na face medial do braço. Em seguida realizou-se o rebatimento da pele e tela subcutânea, secção transversal dos músculos peitorais superficial e profundo próximo ao esterno e individualização do nervo radial, seguido do seu isolamento das demais estruturas vásculo-nervosas circunvizinhas, especialmente, as artérias e veias axilares e braquiais e nervos mediano, ulnar e musculocutâneo.

$\mathrm{Na}$ face lateral do membro torácico, realizou-se procedimento de dissecação, desde a inserção do membro no tórax até a região do carpo, com subseqüente visualização do nervo radial junto à face lateral do músculo braquial.

Após individualização, o nervo radial foi dissecado em direção à origem para se observar quais os ramos ventrais dos nervos espinhais contribuíam para sua formação. Em seguida, procedeu-se a dissecação do nervo distalmente, observando sua distribuição e ramificação na região do braço.

Calcularam-se as freqüências absoluta e relativa, e realizou-se o teste de Tukey $5 \%$ no programa S.A.S. ${ }^{\circledR}$ (Software Analysis System).

A nomenclatura utilizada neste trabalho esteve de acordo com o International Committee on Veterinary Gross Anatomical Nomenclature ${ }^{10}$.

\section{Resultados}

Após emergir pelo espaço axilar, o nervo radial do gato, mostrou-se formado em 11 casos $(18,33 \%)$ pelo ramo ventral do sexto nervo espinhal cervical (C6), e em todos os casos $(100,0 \%)$ pelos ramos ventrais do sétimo (C7) e oitavo (C8) nervos espinhais cervicais e pelo primeiro (T1) torácico.

O nervo radial exibiu simetria em relação a sua origem em 28 animais $(93,33$ $\%$ ), originando-se em 11 casos (18,33\%) do C6 ao T1, exibindo seis casos à direita $(54,55$ $\%$ ) e cinco casos à esquerda (45,45\%), ocorrendo essa disposição em apenas um gato macho no antímero direito. Nos outros 49 casos $(81,67 \%)$, evidenciou-se origem do C7 ao T1, 24 casos à direita $(48,98 \%$ ) e 25 casos à esquerda (51,02\%) (Figura 1A).

Após um curso de aproximadamente dois centímetros, estes ramos se convergem e se unem, constituindo, na altura do terço médio da escápula, sob o músculo subescapular, um tronco nervoso único, o nervo radial, que segue distalmente em direção ao braço, medialmente à artéria braquial e em parte deste percurso em posição medial aos nervos mediano e ulnar.

Próximo ao terço médio do braço, o nervo radial, penetra entre as cabeças medial e acessória do músculo tríceps braquial, ficando caudal à primeira e cranial à segunda. Dorsalmente a este ponto, o nervo radial passa sob o músculo redondo maior, próximo ao seu tendão de inserção. Neste trajeto, o nervo radial, até então, com formato arredondado, passa a assumir uma forma achatada no sentido craniocaudal.

Após sua formação, o nervo radial percorre um trajeto de aproximadamente 0,5 $\mathrm{cm}$ até emitir seu primeiro ramo, próximo à articulação do ombro, a partir daí, o mesmo cede ramos nervosos em todos os animais para as cabeças longa, acessória, medial e lateral do músculo tríceps braquial (Figura 1B), músculo tensor da fáscia antebraquial e músculo ancôneo (Figura 2B). No entanto, evidenciaram-se arranjos peculiares na distribuição destes ramos nervosos em cada exemplar estudado.

Dos ramos emitidos pelo nervo radial durante seu trajeto na região do braço, foi possível distinguir, tanto à direita quanto à 
esquerda, em machos e fêmeas, cinco ramificações (Figuras 2A e 2B).

Durante este trajeto, o nervo radial emite de 14 a 25 ramos musculares (Tabela 1). Entretanto, cada músculo recebe um número distinto de ramos nervosos (Tabelas 2 e 3).

A análise estatística dos resultados revelou diferença significativa ao nível de 5,0 $\%(\mathrm{p}<0,05)$ para as comparações efetuadas na origem do nervo radial quando confrontados os sexos. No entanto, não ocorreu diferença significativa quando comparados os resultados da ramificação e distribuição do referido nervo, se confrontado o sexo e os antímeros.

\section{Discussão}

As informações encontradas na literatura consultada, referentes à origem, ramificação e distribuição do nervo radial, mostraram-se semelhantes às constatadas no presente estudo, tal quais as observações concernentes à formação e ao curso deste nervo no braço do gato, visto que o mesmo é considerado o maior nervo espinhal que compõe o plexo braquial do cão ${ }^{11,12,13,14}$, do gato ${ }^{15}$ e dos animais domésticos ${ }^{16}$.

Assim, o nervo radial no gato doméstico, emerge do plexo braquial a partir dos ramos ventrais do sétimo e oitavo nervos espinhais cervicais e do primeiro nervo espinhal torácico conforme descreveram Crouch $^{17}$, Reimers citado por Getty ${ }^{18}$, Hudson e Hamilton ${ }^{19}$ e Dyce, Sack e Wensing ${ }^{20}$, recebendo em $18,33 \%$ dos exemplares a contribuição do ramo ventral do sexto nervo espinhal cervical, concordando com Reimers citado por Getty ${ }^{18}$. Embora o ramo ventral

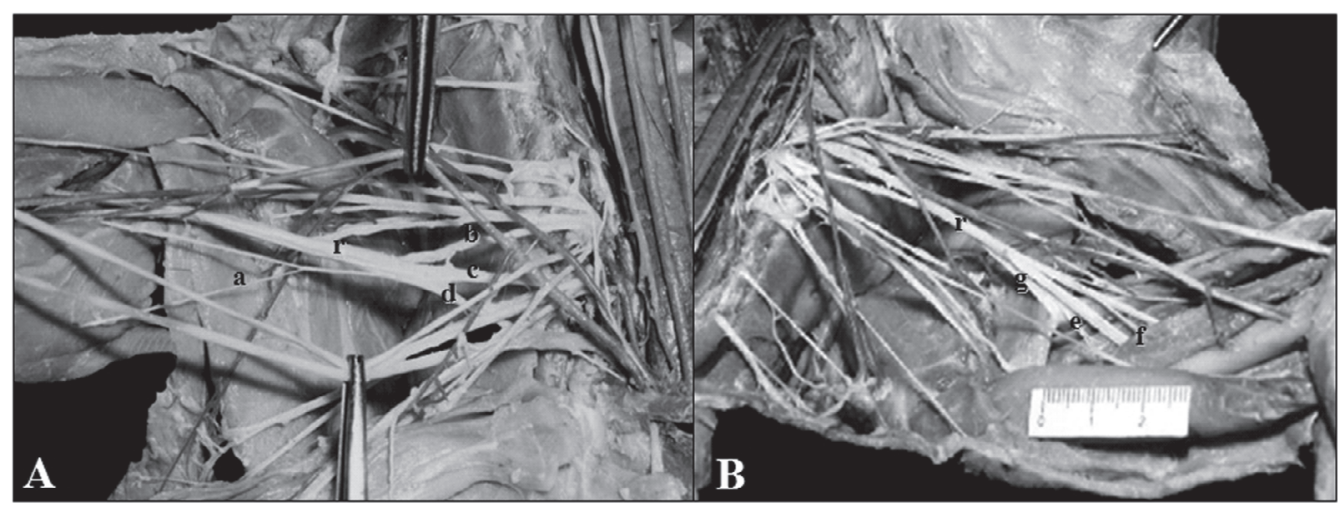

Figura 1 - Fotografia da região axilar direita, de um gato doméstico fêmea, onde se observa em $\mathrm{A}$ ) os ramos ventrais do sétimo (b) e oitavo (c) nervos espinhais cervicais e do primeiro torácico (d), o nervo radial (r) e ramo nervoso destinado ao músculo tensor da fáscia antebraquial (a); em B) ramos nervosos enviados para as cabeças acessória (e), medial (f) e longa (g) do músculo tríceps braquial

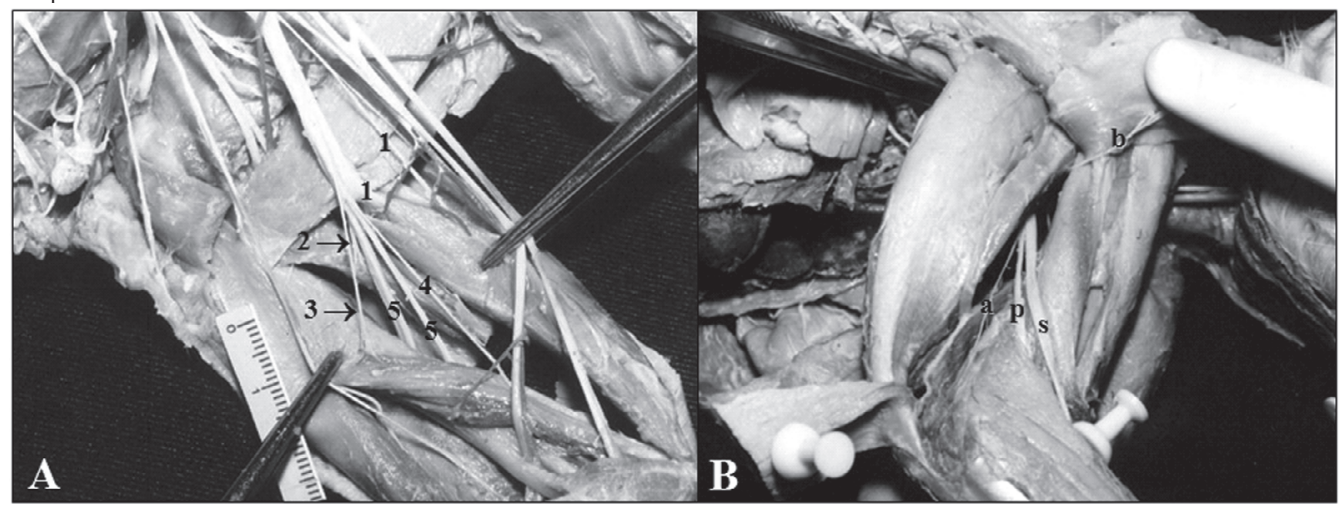

Figura 2 - Fotografia do plexo braquial direito, de um gato doméstico fêmea, onde se observa em A) Vista medial: a primeira (1), a segunda (2), a terceira (3), a quarta (4) e a quinta ramificação (5) do nervo radial; em B) Vista lateral: verificam-se ramos nervosos para os músculos ancôneo (a) e cabeça lateral do tríceps braquial (b), os ramos superficial (s) e profundo (p) do nervo radial 
Tabela 1 - Número de ramos cedidos pelo nervo radial durante seu trajeto na região do braço do gato doméstico de acordo com o sexo do animal. Faculdade de Ciências Agrárias e Veterinárias, UNESP, Jaboticabal - SP, 2005

\begin{tabular}{|c|c|c|c|c|c|c|c|c|c|c|c|c|}
\hline \multirow[t]{2}{*}{ Sexo } & \multicolumn{12}{|c|}{ Número de ramos (\%) } \\
\hline & 14 & 15 & 16 & 17 & 18 & 19 & 20 & 21 & 22 & 23 & 24 & 25 \\
\hline Fêmea & - & 3,33 & - & 6,37 & 6,67 & 23,33 & 6,67 & 26,67 & 13,33 & 6,67 & - & 6,67 \\
\hline Macho & 3,33 & - & 3,33 & 10,00 & 16,67 & 23,33 & 6,67 & 13,33 & 13,33 & 3,33 & 6,67 & - \\
\hline
\end{tabular}

Tabela 2 - Freqüência do número de ramos emitidos pelo nervo radial aos músculos tensor da fáscia antebraquial (TFA), ancôneo (ANC), e às cabeças longa (CLO), acessória (CAT), medial (CMT) e lateral (CLT) do músculo tríceps braquial em gatos fêmeas, por antímero. Faculdade de Ciências Agrárias e Veterinárias, UNESP, Jaboticabal - SP, 2005.

\begin{tabular}{|c|c|c|c|c|c|c|c|}
\hline \multirow{2}{*}{$\begin{array}{c}\text { Número de } \\
\text { Ramos }\end{array}$} & \multirow{2}{*}{ Antímero } & \multicolumn{6}{|c|}{ Músculos } \\
\hline & & $T F A$ & CLO & $C A T$ & $C M T$ & $C L T$ & $A N C$ \\
\hline \multirow{2}{*}{1} & $\mathrm{D}$ & - & - & - & 3,33 & - & - \\
\hline & $\mathrm{E}$ & - & - & - & 13,33 & - & - \\
\hline \multirow{2}{*}{2} & $\mathrm{D}$ & 16,67 & - & - & 26,67 & - & 100,00 \\
\hline & $\mathrm{E}$ & 23,33 & - & - & 20,00 & 6,67 & 100,00 \\
\hline \multirow{2}{*}{3} & $\mathrm{D}$ & 26,67 & - & 3,33 & 16,67 & 13,33 & - \\
\hline & $\mathrm{E}$ & 20,00 & 3,33 & 6,67 & 13,33 & 3,33 & - \\
\hline \multirow{2}{*}{4} & $\mathrm{D}$ & 6,67 & 16,67 & 6,67 & 3,33 & 26,67 & - \\
\hline & $E$ & 6,67 & 13,33 & 13,33 & - & 20,00 & - \\
\hline \multirow{2}{*}{5} & $\mathrm{D}$ & - & 33,33 & 10,00 & - & 10,00 & - \\
\hline & $E$ & - & 23,33 & 20,00 & 3,33 & 20,00 & - \\
\hline \multirow{2}{*}{6} & $\mathrm{D}$ & - & - & 30,00 & - & - & - \\
\hline & $E$ & - & 6,67 & 10,00 & - & - & - \\
\hline \multirow{2}{*}{7} & $\mathrm{D}$ & - & - & - & - & - & - \\
\hline & E & - & 3,33 & - & - & - & - \\
\hline
\end{tabular}

do segundo nervo espinhal torácico possa participar da formação do nervo radial ${ }^{19}$, não se observou esta ocorrência nos animais ora estudados.

A convergência destes ramos nervosos para formar um tronco nervoso único, isto é, o nervo radial, ocorre sob o músculo subescapular, após percorrerem uma distância de aproximadamente $2 \mathrm{~cm}$ na região axilar, em direção ao braço, mediocaudalmente à artéria braquial, conforme descreveu Evans ${ }^{14}$ e Cattelan et al. ${ }^{21}$ no cão e por Dyce, Sack e Wensing ${ }^{20}$ nos carnívoros. Em parte deste percurso, o nervo radial corre em posição medial aos nervos mediano e ulnar, com os quais percorre um trajeto comum concordando com as afirmações de Bradley ${ }^{11}$, Evans ${ }^{14}$ e Cattelan et al. ${ }^{21}$ para o cão e de Reimers citado por Getty ${ }^{18}$ para o gato.

Aproximadamente no terço médio do braço, o nervo radial penetra entre as cabeças medial e acessória do músculo tríceps braquial, situando-se caudalmente a primeira destas porções musculares e cranialmente a segunda, concordando com as descrições de Crouch $^{17}$ para o gato. De acordo com Bradley $^{11}$, Evans ${ }^{14}$ e Cattelan et al. ${ }^{21}$ para o cão, com Ghoshal ${ }^{15}$, Reimers citado por Getty $^{18}$ e Hudson e Hamilton ${ }^{19}$ para o gato e 
Tabela 3 - Freqüência do número de ramos emitidos pelo nervo radial aos músculos tensor da fáscia antebraquial (TFA), ancôneo (ANC), e às cabeças longa (CLO), acessória (CAT), medial (CMT) e lateral (CLT) do músculo tríceps braquial em gatos machos, por antímero. Faculdade de Ciências Agrárias e Veterinárias, UNESP, Jaboticabal - SP, 2005

\begin{tabular}{|c|c|c|c|c|c|c|c|}
\hline \multirow{2}{*}{$\begin{array}{c}\text { Número de } \\
\text { Ramos }\end{array}$} & \multirow{2}{*}{ Antimero } & \multicolumn{6}{|c|}{ Músculos } \\
\hline & & $T F A$ & CLO & $C A T$ & $C M T$ & $C L T$ & $A N C$ \\
\hline \multirow{2}{*}{1} & $\mathrm{D}$ & - & - & - & - & - & - \\
\hline & $\mathrm{E}$ & 3,33 & - & - & 3,33 & - & - \\
\hline \multirow{2}{*}{2} & $\mathrm{D}$ & 26,67 & - & - & 23,33 & - & 100,00 \\
\hline & E & 13,33 & - & 3,33 & 33,33 & 6,67 & 100,00 \\
\hline \multirow{2}{*}{3} & $\mathrm{D}$ & 10,00 & 10,00 & - & 23,33 & 13,33 & - \\
\hline & $\mathrm{E}$ & 23,33 & 16,67 & 10,00 & 10,00 & 3,33 & - \\
\hline \multirow{2}{*}{4} & $\mathrm{D}$ & 13,33 & 26,67 & 23,33 & - & 26,67 & - \\
\hline & $\mathrm{E}$ & 10,00 & 23,33 & 13,33 & 3,33 & 20,00 & - \\
\hline \multirow{2}{*}{5} & D & - & 13,33 & 23,33 & - & 10,00 & - \\
\hline & $E$ & - & 10,00 & 10,00 & - & 20,00 & - \\
\hline \multirow{2}{*}{6} & $\mathrm{D}$ & - & - & 3,33 & 3,33 & - & - \\
\hline & $\mathrm{E}$ & - & - & 13,33 & - & - & - \\
\hline \multirow{2}{*}{7} & D & - & - & - & - & - & - \\
\hline & $\mathrm{E}$ & - & - & - & - & - & - \\
\hline
\end{tabular}

com Dyce, Sack e Wensing ${ }^{20}$ para os carnívoros, o referido nervo penetra nesta mesma região, embora entre as cabeças medial e longa do músculo tríceps braquial.

$O$ nervo radial no gato assume formato cilíndrico logo após sua origem, tornando-se achatado na direção craniocaudal, pouco antes de penetrar as cabeças acessória e medial do músculo tríceps braquial, assemelhando-se aos relatos de Cattelan et al. ${ }^{21}$ para o cão.

Aproximadamente a meio centímetro de sua origem, próximo à articulação do ombro, o nervo radial inicia suas ramificações originando os ramos destinados aos músculos extensores do braço, ou seja, aos músculos tríceps braquial (cabeças longa, medial, acessória e lateral), tensor da fáscia antebraquial e ancôneo, concordando com os relatos de Stefanatos ${ }^{22}$ para o cão, de Crouch $^{17}$, Ghoshal ${ }^{15}$ e Hudson e Hamilton ${ }^{14}$ para o gato, de Dyce, Sack e Wensing ${ }^{20}$ para os carnívoros e de Frandson ${ }^{16}$ para os animais domésticos. Segundo Ghoshal ${ }^{15}$ e Hudson e Hamilton $^{19}$ o músculo braquiorradial, no gato, também recebe fibras provenientes do nervo radial, no entanto, não foram encontradas ocorrências destes ramos nos animais do presente estudo.

Em seguida, o nervo radial segue distalmente em direção ao músculo braquial, espiralando-se ao redor do úmero conforme descreveu Evans ${ }^{14}$ e Cattelan et al. ${ }^{21}$ para o cão e Dyce, Sack e Wensing ${ }^{20}$ para os carnívoros, emergindo na face lateral do braço, próximo à superfície flexora do cotovelo, concordando com os relatos de Ghosha ${ }^{15}$ e Hudson e Hamilton ${ }^{19}$ para o gato e de Dyce, Sack e Wensing ${ }^{20}$ para os carnívoros, junto à face lateral do músculo braquial e à face craniomedial da cabeça lateral do músculo tríceps braquial, semelhante ao descrito no cão por Cattelan et al. ${ }^{21}$.

Embora Evans ${ }^{14}$ e Cattelan et al. ${ }^{21}$ aludam ao fato de que o nervo radial no cão relacione-se com a artéria nutrícia do úmero e que no gato ${ }^{15}$, além de relacionar-se com este vaso, mantêm proximidade com a artéria radial colateral durante sua passagem da face 
medial para a face lateral do braço, tais situações não foram notadas nos animais do presente estudo.

No terço distal da face lateral do braço, o nervo radial mostrou-se formado por dois ramos, o profundo e o superficial, entretanto, esta divisão já é aparente no terço médio do braço, concordando com as descrições feitas para o cão ${ }^{14,21,23}$, para o gato ${ }^{15,17,19}$ e para os carnívoros ${ }^{20}$. Embora Crouch $^{17}$ discuta no gato, Stefanatos ${ }^{22}$ e Evans $^{14}$ no cão, que os ramos profundo e superficial do nervo radial possuam função, respectivamente, motora e sensitiva, nossos experimentos não foram conclusivos sobre a funcionalidade deste nervo, havendo necessidade de pesquisas mais detalhadas sobre o assunto.

$\mathrm{Na}$ face lateral do braço, o ramo profundo do nervo radial posiciona-se caudalmente ao ramo superficial, seguindo distalmente em direção ao antebraço e depois entre os músculos braquial e extensor radial do carpo, corroborando com as descrições feitas para o gato ${ }^{15,17,19}$ e para os carnívoros ${ }^{20}$.

Já o ramo superficial do nervo radial posiciona-se obliquamente na porção distal do braço, na direção craniodistal, entre os músculos braquiorradial e extensor radial do carpo, estando encoberto por uma espessa fáscia muscular, dividindo-se em ramos medial e lateral, que seguem em direção ao antebraço margeando, respectivamente, as faces medial e lateral da veia cefálica, semelhante ao descrito no cão por Cattelan et al. ${ }^{21}$, Evans ${ }^{14}$ e Habel $^{24}$, no gato por Crouch $^{17}$, Ghoshal ${ }^{15}$ e Hudson e Hamilton ${ }^{19}$ e nos carnívoros por Dyce, Sack e Wensing ${ }^{20}$.
Quanto às ramificações do nervo radial, destinados aos músculos extensores do braço, pode-se notar nesta investigação, que elas ocorrem quase simultaneamente, quando o nervo radial penetra na face medial entre as cabeças medial e acessória do músculo tríceps braquial, situação que explica como lesões altas neste nervo, incapacitam a locomoção do animal, em decorrência da deficiência motora que se instala, fato demonstrado em neurectomias experimentais por Knecht e Saint Clair ${ }^{25}$ e Worthman ${ }^{1}$.

Em síntese, os resultados desta investigação mostram que os músculos supridos pelo nervo radial no braço do gato doméstico são o tríceps braquial (cabeças longa, acessória, medial e lateral), tensor da fáscia antebraquial e ancôneo, reiterando as citações feitas para o cão ${ }^{11,13,14,16,21}$, para o gato ${ }^{15,17,18,19}$ e para os carnívoros ${ }^{20}$.

\section{Conclusões}

Destaca-se neste trabalho a importância do conhecimento detalhado da origem, da ramificação e da distribuição dos nervos espinhais, entidades funcionalmente relevantes, como no caso do nervo radial, responsável pela inervação motora dos músculos extensores na região do braço, propiciando assim, subsídios morfológicos referentes ao sistema nervoso periférico da espécie felina.

Portanto, o estudo comparativo entre o cão e o gato demonstra particularidades inerentes aos carnívoros, possíveis de serem encontradas nestas espécies, no entanto, fica claro que diferenças e variações anatômicas podem ocorrer.

The radial nerve origin, ramification and distribution in the arm of the domestic cat (Felis catus domesticus, Linnaeus 1758)

\footnotetext{
Abstract

The origin and distribution of the radial nerves were studied in 30 adult domestic cats. The sample included 15 females and 15 males of unknown breed. The specimens were fixed in $10 \%$ formaldehyde solution. Radial nerves were observed to originate, in 11 cases (18.33 $\%$ ), from the ventral branch of the sixth cervical spinal nerve; in 60 cases $(100.0 \%)$, from the ventral branch of the seventh cervical
}

Key words: Ramification Distribution. Radial nerve. Cat. 
spinal nerve; in 60 cases $(100.0 \%)$, from the ventral branch of the eight cervical nerve and in 60 cases $(100.0 \%$ ), from the ventral branch of the first thoracic nerve. The radial nerves branched out, in all of the animals studied, to the tensor fasciae antebrachii, long, accessory, medial and lateral heads of the triceps branchii and anconeus muscles. The radial nerve emits of 14 to 25 nervous branches in the arm region. However, the branch of the sixth cervical spinal nerve reveal significant differences $(p<0.05)$ with relation to sex of the animals.

Extrato de Dissertação de Mestrado - Apoio financeiro Fapesp: 01/10473-6

\section{Referências}

1 WORTHMAN, R. P. Demonstration of specific nerve paralysis in the dog. Journal of the American Veterinary Medicine Association, v. 131, n. 1, p. 174, 1957.

2 CHRISMAN, C. L. Neurologia dos pequenos animais. 1. ed. São Paulo: Roca, 1985. p. 371-386.

3 CHANDLER, E. A.; HILBERY, A. D. R.; GASKELL, C. J. Medicina e terapêutica de felinos. 2. ed. São Paulo: Manole, 1988. p. 66-67.

4 DENNY, H. R. A guide to canine and feline orthopedic surgery. 3. ed. Oxford: Blackwell Scientific Publications, 1993. p. 122-124.

5 FENNER, W. R. Diseases of the brain, spinal cord and peripheral nerves. In: SHERDING, G. R. The cat diseases and clinical management. 2. ed. Philadelphia: W. B. Saunders, 1994. p. 1507-1568.

6 OLIVER, J. E.; LORENZ, M. D.; KORNEGAY, J. N. Handbook of veterinary neurology. 3. ed. Philadelphia: W. B. Saunders, 1997. p. 115-117.

7 RODKEY, W. G. Cirurgia dos nervos periféricos. In: SLATTER, D. Manual de cirurgia de pequenos animais. 2. ed. São Paulo: Manole, 1998. p. 1360-1368.

8 SHAW, D.; IHLE, S. Medicina interna de pequenos animais. Porto Alegre: Artmed, 1999. p. 542-543.

9 BROWN, P. W. Factors influencing the success of the surgical repair of peripheral nerves. Surgical Clinics of North America, v. 52, n. 5, p. 1137-1155, 1972.

10 INTERNATIONAL COMMITTEE ON VETERINARY GROSS ANATOMICAL NOMENCLATURE. Nomina anatomica veterinaria. 4. ed. New York: World Association on Veterinary Anatomist, 1994. 198 p. (Together with nomina histologica, 2. ed., 1992 and nomina embryologica veterinaria, 1992).

11 BRADLEY, O. C. Topographical anatomy of the dog. 5. ed. Edinburgh: Oliver and Boyd, 1948. p. 5, 156, 163-164, 171.

12 ALLAM, M. W.; LEE, D. G.; NULSEN, F. E.; FORTUNE, E. A. The anatomy of the brachial plexus of the dog. The Anatomical Record, v. 114, p. 173$180,1952$.
13 ADAMS, D. R. Anatomía canina: estudio sistémico. Zaragoza: Acribia, 1988. p. 413-421.

14 EVANS, H. E. Miller's anatomy of the dog. 3. ed. Philadelphia: W. B. Saunders, 1993. 1113 p.

15 GHOSHAL, N. G. The brachial plexus (plexus brachialis) of the cat (felis domesticus). Zentralblatt Fur Veterinarmedizin Reithe C, v. 1, p. 6-13, 1972.

16 FRANDSON, R. D. Anatomy and physiology of farms animals. 5. ed. Philadelphia: Lea \& Febiger, 1992. 572 p.

17 CROUCH, J. E. Text-atlas of cat anatomy. Philadelphia: Lea \& Febiger, 1969. p. 230-242, 259266.

18 GETTY, R. Sisson/Grossman anatomia dos animais domésticos. 5. ed. Rio de Janeiro: Interamericana, 1981. p. 1607-1617.

19 HUDSON, L. C.; HAMILTON, W. P. Atlas of feline anatomy for veterinarians. 1. ed. Philadelphia: W. B. Saunders, 1993. p. 213-219.

20 DYCE, K. M.; SACK, W. O.; WENSING, C. J. G. Tratado de anatomia veterinária. 3 . ed. Rio de Janeiro: Guanabara Koogan, 2004. p. 451-453.

21 CATTELAN, J. W.; FERREIRA, N.; CATTELAN, G. M. G.; MALHEIROS, E. B. Estudo anatômico da ramificação e distribuição fascicular do nervo radial no braço de cão (Canis familiaris, Linnaeus, 1758). Ars Veterinária, v. 12, n. 2, p. 163-172, 1996.

22 STEFANATOS, J. Treatment to reduce radial nerve paralysis. Veterinary Medicine, p. 67-71, 1984.

23 SCHWARZE, E.; SCHRÖDER, L. Compendio de anatomia veterinaria: sistema nervoso y organos de los sentidos. Zaragoza: Acribia, 1970. p. 67, 70-72.

24 HABEL, R. E. Anatomia veterinária aplicada. Zaragoza: Acribia, 1988. p. 82-91.

25 KNECHT, C. D.; SAINT CLAIR, L. E. The radialbrachial paralysis syndrome in the dog. Journal of the American Veterinary Medical Association, v. 154, n. 6, p. 653-656, 1969. 